\title{
Levonorgestrel intrauterine contraceptive device in heavy menstrual bleeding: our experience in a tertiary level government hospital
}

\author{
Renuka Malik*, Jagrati Gupta, P. Singh, Poonam Yadav
}

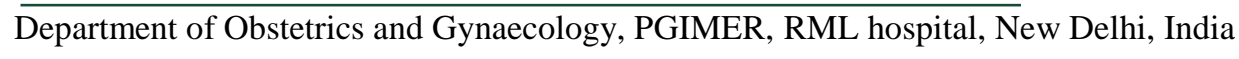

Received: 08 November 2015

Revised: 17 November 2015

Accepted: 07 January 2016

\section{*Correspondence:}

Dr. Renuka Malik,

E-mail: renucam@yahoo.co.in

Copyright: (c) the author(s), publisher and licensee Medip Academy. This is an open-access article distributed under the terms of the Creative Commons Attribution Non-Commercial License, which permits unrestricted non-commercial use, distribution, and reproduction in any medium, provided the original work is properly cited.

\begin{abstract}
Background: The aim of the study was to assess the effect of levonorgestrel intrauterine contraceptive device (LNGIUCD) on menstrual blood loss and its acceptance in Indian women with Heavy menstrual bleeding (HMB).

Methods: 50 women with $\mathrm{HMB}$ and meeting the inclusion criteria were enrolled in the prospective non-randomized observational study from November 2013-2014 in PGIMER, RML HOSPITAL, a tertiary care hospital. LNG-IUCD was inserted and patients were followed up for six months. Reduction in menstrual blood loss, reduction in endometrial thickness, improvement in hemoglobin and serum ferritin and side effects due to LNG-IUCD was noted. Results: LNG-IUCD was effective in 47 out of 50 patients suffering from HMB. There was $98 \%$ reduction in menstrual blood loss (PBAC score) and $67.8 \%$ reduction in endometrial thickness after six months. Improvement in hemoglobin was by $2.44 \mathrm{gm} / \mathrm{dl}$ whereas serum ferritin improved by $15.39 \mu \mathrm{g} / \mathrm{l}$ after 6 months. Relief in dysmenorrhea was $94.7 \%$. Complete amenorrhea was achieved in $19.14 \%$ and $44.6 \%$ were suffering from spotting. Treatment failure was seen in 3 patients who expelled LNG-IUCD at varying intervals. One patient with misplaced LNG-IUCD was relieved of symptoms after repositioning. Proper counseling prior to insertion and after insertion made LNGIUCD well accepted in our study population.

Conclusions: LNG-IUCD is an effective and acceptable non-surgical alternative to a common problem of HMB. The success rate was $94 \%$ in our study with only 3 patients needing hysterectomy due to expulsion. Emphasis on counseling patients of troublesome spotting and correct fundal placement is essential.
\end{abstract}

Keywords: LNG-IUCD, HMB, AUB

\section{INTRODUCTION}

LNG-IUCD was first designed and introduced by Dr. Tapani Luukainen in 1976 for contraception. A major non-contraceptive use of LNG-IUCD is in reduction of menstrual blood loss due to anti-proliferative action of levonorgestrel on uterine endometrium which causes atrophy of endometrial glands and decidualization of stroma leading to thinning of endometrium. Due to this effect of LNG-IUCD it was approved by FDA (USA) in 2009 and by Canada in 2010 for use in heavy menstrual bleeding (HMB).
HMB is a common gynaecological disorder which effects about $10-15 \%$ of women in their reproductive age group. ${ }^{1,2}$ HMB was objectively defined as menstrual blood loss of $80 \mathrm{ml}$ or greater per cycle. ${ }^{3}$ In 2007 , NICE defined heavy menstrual bleeding as "excessive menstrual blood loss which interferes with the woman's physical, emotional, social and material quality of life, and which can occur alone or in combination with other symptoms. ${ }^{4}$ HMB leads to iron deficiency anaemia. ${ }^{3,5}$ According to the data from national family health survey ${ }^{6}$ more than half $(55 \%)$ of women in India have anaemia. HMB further aggravates the condition. 
A variety of medical and surgical treatment modalities are available to treat HMB. In the medical management options includes anti-fibrinolytics, non-steroidal antiinflammatory drugs, the combined oral contraceptive pill, oral progestins, danazol, gonadotropin releasing hormone agonists and levonorgestrel intrauterine system (LNGIUCD). Surgical management includes conservative procedures like endometrial destruction (endometrial resection and ablation) and definitive procedure such as hysterectomy.

LNG IUCD is an acceptable nonsurgical alternative for women suffering from HMB considering its ease of insertion, efficacy, better acceptability, low side effect profile and benefits of contraception. Since there is paucity of data regarding effectiveness of LNG-IUCD in reducing menstrual blood loss and its acceptance in Indian females the present study aims at evaluating the same.

\section{METHODS}

This study was conducted at PGIMER, RML hospital New Delhi, which is a tertiary level CGHS hospital from November 2013 to November 2014. In this nonrandomized prospective clinical trial, 50 women aged between 35-45 years suffering from HMB at least for three months and willing for long term contraception were enrolled for LNG-IUCD insertion. Patients with genital malignancy severely distorted endometrial cavity due to fibroid uterus diagnosed on hysteroscopy, uterus size $>12$ weeks, any severe medical disorder were excluded from the study. A detailed gynecological, obstetrics, medical and surgical history was taken. Menstrual history included number of days of bleeding, number of sanitary pads used and amount of their soakage, passage of clots, episodes of flooding and dysmenorrhoea. General physical and gynecological examination was done. Pap's smear and endometrial sampling were done in all patients to rule out malignancy. Patients were classified according to PALM-COEIN classification given by FIGO in 2011 for abnormal uterine bleeding (AUB). The histopathology report was used to classify ovulatory dysfunction in our study; however FIGO recommends it to be classified according to history and excluding structural lesions in abnormal uterine bleeding.

Hemoglobin and serum ferritin levels were checked in all patients selected for study. Ultrasonography was done to assess endometrial thickness and size of fibroid if any. Hysteroscopy was done in patients to evaluate the endometrial cavity for any distortion if ultrasonography is inconclusive and if endometrial thickness was more than $11 \mathrm{~mm}$.

Baseline PBAC score of previous month was calculated by PBAC (Pictorial blood assessment chart) filled by the patient according to menstrual history by recall method.
Similarly, baseline values of endometrial thickness, hemoglobin $(\mathrm{Hb})$, serum ferritin were obtained.

LNG-IUCD was inserted in the post menstrual phase and patients were followed up at 1 month to check for any complaints and confirmation of LNG-IUCD in situ. Patients were again called at 3 months when their PBAC score of previous months were noted, $\mathrm{Hb}$ and serum ferritin were measured, ultrasound for endometrial thickness and size of fibroid was done and any hormonal side effects were noted. Similar follow up was done at 6 months. Patients were provided with 24 hours accessibility and counseling.

LNG-IUCD used in the study is marketed by BayerZydus under the commercial name "Mirena". It is a Tshaped polyethylene frame with both horizontal and vertical limbs measuring $32 \mathrm{~mm}$ each. The polyethylene is compounded with barium sulfate to make it radioopaque. There is a reservoir attached to vertical limb consisting of levonorgestrel and polydimethylsiloxane covered by a silicone membrane. A total of $52 \mathrm{mg}$ of levonorgestrel is present in the vertical limb and 20 $\mu \mathrm{g} /$ day is released daily for 5 years. $^{7}$ A monofilament brown thread is attached to a loop at the end of the vertical stem of the T-body. ${ }^{8}$ This thread is composed of polyethylene with $1 \%$ ferric oxide.

The PBAC chart used in this study was described by Hingham JM et al in 1990. A PBAC score of greater than or equal to 100 is equivalent to menstrual blood loss of greater than or equal to $80 \mathrm{ml}$ and was considered diagnostic of heavy menstrual bleeding. ${ }^{9}$

Spotting was defined as occasional unpredictable blood stained vaginal discharge requiring minimal or no protection. Treatment failure was defined as PBAC score any time more than 100, expulsion of LNG-IUCD and patient having any severe side effect and insisting for removal.

\section{Statistical analysis}

Statistical software package SPSS was used for analysis of data. Paired-T test was used to evaluate changes in endometrial thickness and hemoglobin levels. Wilcoxon signed rank test which is a non-parametric test was applied on PBAC score and serum ferritin levels.

\section{RESULTS}

Patients in our study population were between 35-45 years with mean $\pm \mathrm{SD}$ of age being $41.22 \pm 3.8$ years. Before insertion the mean $\pm \mathrm{SD}$ of PBAC score in 50 patients was $1074.8 \pm 541.84$. The mean \pm SD of $\mathrm{Hb}$ in our study population was $10.13 \pm 1.38 \mathrm{gm} / \mathrm{dl}$. The mean $\pm \mathrm{SD}$ of S.ferritin in 50 patients was $2.75 \pm 10.08 \mu \mathrm{g} / \mathrm{l}$ preinsertion signifying depleted stores. The mean \pm SD ET before insertion was $12.09 \pm 4.18 \mathrm{~mm}$. 
Out of 50 patients, 26 (52\%) had ovulatory dysfunction, 2 (4\%) had simple endometrial hyperplasia without atypia, $3(6 \%)$ had fibroid as the cause, $2(4 \%)$ had adenomyosis, $4(8 \%)$ had fibroid and ovulatory dysfunction, $5(10 \%)$ had adenomyosis and ovulatory dysfunction, 6 (12\%) had not classified, 1 (2\%) patient had fibroid, adenomyosis and ovulatory dysfunction and one $(2 \%)$ patient had endometrial polyp with fibroid with ovulatory disorder. In the last patient endometrial polyp was removed but the patient still had persistent HMB (Table1). According to histopathology report, 37 (74\%) had proliferative endometrium, $11(22 \%)$ had secretory endometrium and $2(4 \%)$ patients had simple endometrial hyperplasia without atypia.

Table 1: Distribution of patients according to cause of HMB.

\begin{tabular}{|ll|}
\hline Cause & Frequency (\%) \\
\hline $\begin{array}{l}\text { Ovulatory dysfunction ( AUB-O) } \\
\text { without atypia (AUB-M) }\end{array}$ & $26(52 \%)$ \\
\hline Fibroid (AUB-L) & $2(4 \%)$ \\
\hline $\begin{array}{l}\text { Fibroid and ovulatory dysfunction } \\
\text { (AUB L; O) }\end{array}$ & $3(6 \%)$ \\
\hline Adenomyosis (AUB-A) & $4(8 \%)$ \\
\hline $\begin{array}{l}\text { Adenomyosis and ovulatory } \\
\text { dysfunction (AUB A;O) }\end{array}$ & $2(4 \%)$ \\
\hline $\begin{array}{l}\text { Adenomyosis, fibroid and ovulatory } \\
\text { dysfunction ( AUB A;L;O) }\end{array}$ & $5(10 \%)$ \\
\hline $\begin{array}{l}\text { Polyp, fibroid and ovulatory } \\
\text { dysfunction (AUB P;L; O) }\end{array}$ & $1(2 \%)$ \\
\hline No cause identified (AUB-N) & $6(12 \%)$ \\
\hline Total (n) & 50 \\
\hline
\end{tabular}

The insertion technique was simple and required no analgesia. No patient required any dilatation prior to insertion. No incidence of perforation was seen during insertion. No other immediate side effect following insertion was noted. Outcome of patients over 6 months follow up is shown in Figure 1.

After 3 months the mean \pm SD of PBAC score was $80.69 \pm 102.382$ which further reduced to $12.74 \pm 32.523$ at the end of 6 months. There was $90.80 \pm 13.39 \%$ reduction in mean PBAC score at the end of 3 months $(\mathrm{p}=0.00)$ and $98.18 \pm 4.68 \%$ reduction at the end of 6 months $(p=0.00)$ (Figure 2).

The mean $\pm \mathrm{SD}$ of $\mathrm{Hb}$ improved from baseline value of $10.13 \pm 1.38 \mathrm{gm} / \mathrm{dl}$ to $11.4 \pm 1.09 \mathrm{gm}$ at the end of 3 months and to $12.62 \pm 0.80 \mathrm{gm} / \mathrm{dl}$ at 6 months. There was improvement of $13.95 \pm 9.61 \%$ at the end of 3 months and improvement of $25.78 \pm 15.14 \%$ at the end of 6 months. The improvement was statistically significant with $\mathrm{p}$ value $<0.001$ (Figure 3).

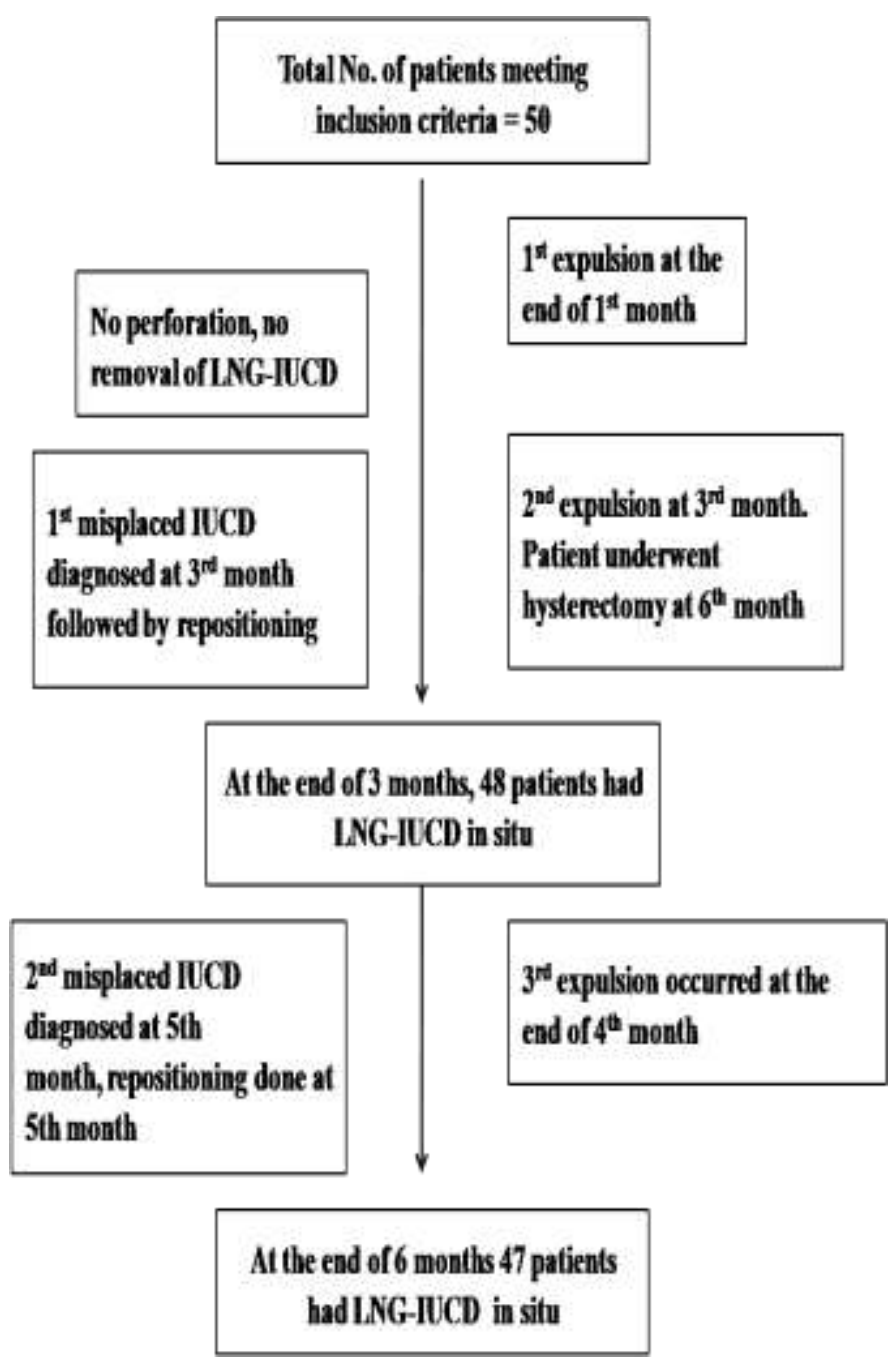

Figure 1: Outcome of study population at 1,3 and 6 months.

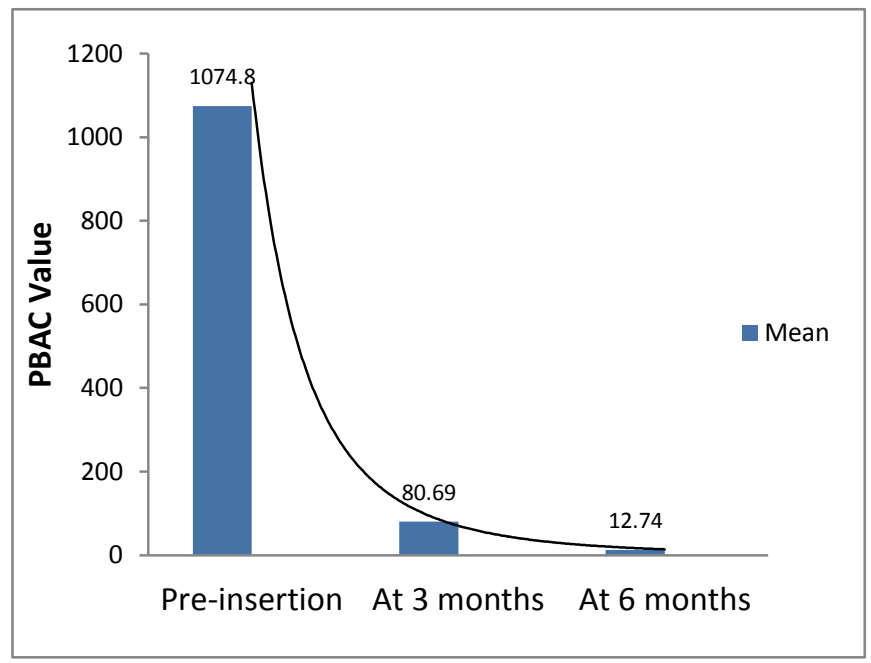

Figure 2: Reduction in mean PBAC scores over 6 months. 

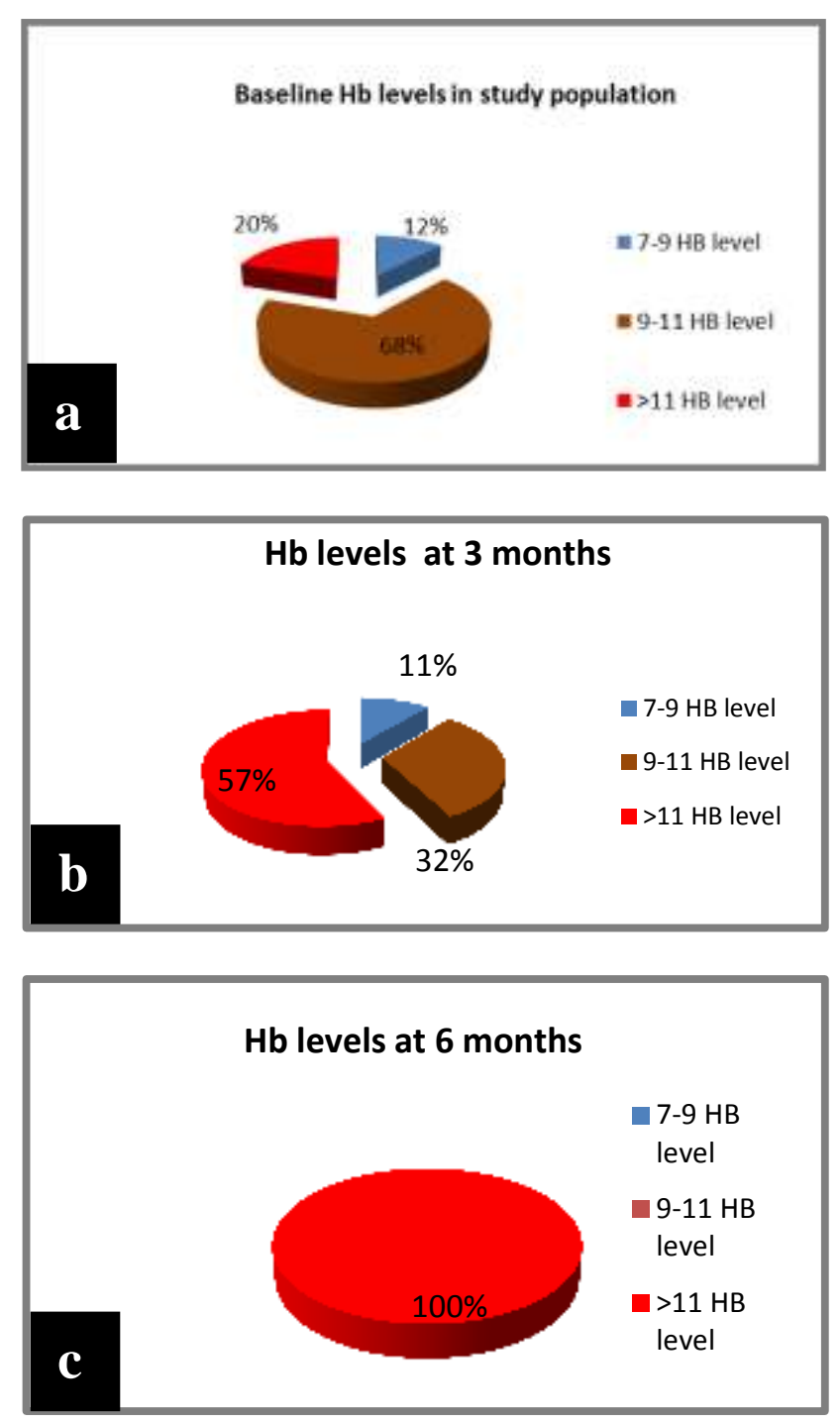

Figure 3: Improvement in $\mathrm{Hb}$ levels seen in study population over 6 months. (a) Baseline $\mathrm{Hb}$ levels in study population; (b) Hb levels at 3 months; (c) $\mathrm{Hb}$ levels at 6 months.

The mean $\pm \mathrm{SD}$ of $\mathrm{S}$. ferritin of 50 patients is $12.75 \pm 10.08 \mu \mathrm{g} / \mathrm{l}$ pre-insertion. At the end of 3 months it improved to $24.99 \pm 11.128 \mu \mathrm{g} / \mathrm{l}$ and to $40.58 \pm 15.39 \mu \mathrm{g} / \mathrm{l}$ in 6 months which shows the improvement of $15.39 \pm 12.05$ $\mu \mathrm{g} / \mathrm{l}$ with $\mathrm{p}$ value $<0.001$.

The mean \pm SD of ET of $12.09 \pm 4.18 \mathrm{~mm}$ before insertion decreased to $7.42 \pm 2.42 \mathrm{~mm}$ at the end of 3 months and further to $3.61 \pm 1.89 \mathrm{~mm}$ after 6 month. The reduction was $67.89 \pm 16.67 \%$ at the end of follow up which was statistically significant $(\mathrm{p}<0.001)$. There were two patients with simple endometrial hyperplasia without atypia (confirmed on histopathology findings). Ultrasonography showed ET to be $13.4 \mathrm{~mm}$ in one and 14 $\mathrm{mm}$ in the other (baseline value). Patient showed marked reduction in menstrual blood loss and ET reduced to 4 $\mathrm{mm}$ in both the patients at the end of 6 months.
At the end of 3 months, 25 women (52.08\%) were having infrequent cycles associated with scanty menstruation, 16 (33\%) of the patients had regular cycles and 7 (14.58\%) were still suffering from heavy menstrual bleeding. At the end of 6 months complete amenorrhea was achieved in $9(19.14 \%)$ females, $21(44.6 \%)$ females were having spotting, $13(27.65 \%)$ had infrequent cycles, $3(6.38 \%)$ had regular cycles and only $1(2.12 \%)$ had persistent HMB. The one patient with persistent HMB had low placed LNG-IUCD. The change in menstrual pattern like amenorrhea and scanty periods were acceptable to all the women suffering from HMB earlier. Irregular spotting was bothersome because of its unpredictability in timing and patient needed counselling for it (Table 2).

Table 2: Menstrual pattern at 3 months and 6 months.

\begin{tabular}{|lll|}
\hline Menstrual pattern & $\begin{array}{l}3 \text { Months } \\
(\mathbf{n = 4 8 )}\end{array}$ & $\begin{array}{l}6 \text { Months } \\
(\mathbf{n}=47)\end{array}$ \\
\hline Amenorrhea & $0(0 \%)$ & $9(19.14 \%)$ \\
\hline Spotting & $0(0 \%)$ & $21(44.6 \%)$ \\
\hline $\begin{array}{l}\text { Infrequent cycles } \\
\text { with scanty mensus }\end{array}$ & $25(52.08 \%)$ & $13(27.65 \%)$ \\
\hline Regular cycles & $16(33.33 \%)$ & $3(6.38 \%)$ \\
\hline HMB & $7(14.58 \%)$ & $1(2.12 \%)$ \\
\hline
\end{tabular}

$19(38 \%)$ patients out of the total 50 , had dysmenorrhoea in the pre-insertion phase. All of these patients were relieved of dysmenorrhoea at the end of 3 months except one, in whom dysmenorrhoea persisted and was diagnosed with misplaced IUCD at $5^{\text {th }}$ month. Hence, relief in dysmenorrhoea was seen in $94.73 \%$ of patients.
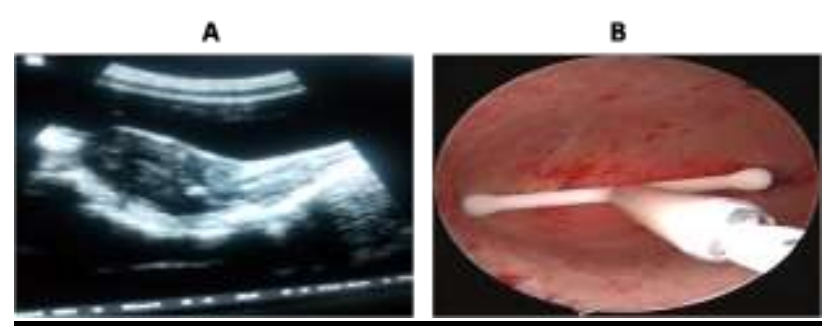

Figure 4: A) Misplaced LNG-IUCD in lower uterine segment, B) Fundal placement of LNG-IUCD by hysteroscopy.

9 patients out of 50 had fibroid uterus of varying size. After LNG-IUCD insertion 3 were relieved of HMB and 3 attained amenorrhea at the end of 6 months. Expulsion was seen in 2 patients, one had multiple fibroids with uterine size of 12 weeks [AUB $-\mathrm{L1}_{(\mathrm{SM})}$ ] and other had single submucosal fibroid of $3 \times 4 \mathrm{~cm}$ with uterine size of 10 weeks $\left[\right.$ AUB-L1 $\left.1_{(\mathrm{SM})}\right]$. Persistent $\mathrm{HMB}$ and misplaced IUCD was seen in one patient in whom there was a submucosal fibroid with intramural component of $3 \times 3 \mathrm{~cm}$ size $\left[\mathrm{AUB}-\mathrm{L} 1_{(\mathrm{SM})}\right]$, diagnosed at $5^{\text {th }}$ month by USG as patient was complaining of persistent HMB. Repositioning was done in this patient under 
hysteroscopic guidance at fundal position; bleeding was found to have reduced during follow ups (Figure 4).

A total of 8 patients were suffering from adenomyosis. One patient suffering from adenomyosis with focal adenomyoma in left cornu with uterus being 12 weeks size expelled the device during her first periods. Remaining $7(87.5 \%)$ were relieved of dysmenorrhoea after 3 months of LNG-IUCD insertion.

Table 3: Frequency distribution of different side effects due to LNG-IUCD.

\begin{tabular}{|lc|}
\hline $\begin{array}{l}\text { Side effects } \\
\text { Weight gain }\end{array}$ & $\begin{array}{c}\text { Number of patients (\% age) } \\
n=47\end{array}$ \\
\hline Backache & $28(59.57 \%)$ \\
\hline Leg pain & $5(10.6 \%)$ \\
\hline Headache & $15(31.9 \%)$ \\
\hline Breast tenderness & $4(8.5 \%)$ \\
\hline Ovarian cyst & $5(10.6 \%)$ \\
\hline
\end{tabular}

Treatment failure in the present study was found in 3(6\%) patients. These patients expelled LNG-IUCD at varying intervals after insertion. One expulsion occurred after one month of LNG-IUCD insertion in a patient with adenomyosis. The other two expulsions occurred at 3rd month and $4^{\text {th }}$ month respectively. Both of these patients had submucosal fibroid uterus. All these patients underwent hysterectomy later on. Few hormonal side effects found after direct questioning were not bothersome to the patients and none asked for removal (Table 3).

\section{DISCUSSION}

LNG-IUCD has a strong local suppressive action on the endometrium leading to glandular atrophy, decidualization of the stroma and inactivation of endometrial cells within three months after insertion and remain unchanged during use of LNG-IUCD. ${ }^{10}$ This action is responsible for its efficacy in HMB. Several studies in the past have indicated LNG-IUCD efficacy in HMB through two different methods-either PBAC or Alkali Hematin (Table 4).

Table 4: Comparison of present study with other studies showing reduction in MBL.

\begin{tabular}{|c|c|c|c|c|}
\hline Studies & Method used & $\begin{array}{l}\% \text { Reduction at } \\
3 \text { months }\end{array}$ & $\begin{array}{l}\% \text { Reduction at } \\
6 \text { months }\end{array}$ & $\begin{array}{l}\text { Level of } \\
\text { significance }\end{array}$ \\
\hline Present study & PBAC & $90.80 \pm 13.39 \%$ & $98.18 \pm 4.68 \%$ & $\mathbf{P}=\mathbf{0 . 0 0}$ \\
\hline J. Kerstein et al 1990 & Alkali hematin & $86 \% *$ & $91 \% *$ & $\mathrm{P}<0.001$ \\
\hline Tang \& Lo 1994 & Alkali hematin & $87 \%$ & $95 \%$ & $\mathrm{P}<0.05$ \\
\hline Barrington et al 1997 & PBAC & $74.16 \%$ & NR & $\mathrm{P}<0.0001$ \\
\hline G.A Irvine et al 1998 & Alkali hematin & $94 \% *$ & NR & $\mathrm{P}<0.005$ \\
\hline Bilian Xiao et al 2003 & Alkali hematin & NR & $78.7 \%$ & $\mathrm{P}<0.001$ \\
\hline Busfield et al 2005 & PBAC & $74.48 \%$ & $85.28 \%$ & $\mathrm{P}<0.05$ \\
\hline $\begin{array}{l}\text { Reid and Virtanen-Kari } \\
2005\end{array}$ & Alkali hematin & $90 \% *$ & $96 \% *$ & $\mathrm{P}<0.005$ \\
\hline Gupta et al 2006 & PBAC & $87 \%$ & $94 \%$ & $\mathrm{P}<0.05$ \\
\hline A.Kriplani et al 2007 & PBAC & $80 \% *$ & $90 \% *$ & NR \\
\hline Shaw et al 2007 & PBAC & $61 \% *$ & $72 \% *$ & NR \\
\hline A.Kaunitz et al 2010 & Alkali hematin & $83.2 \% *$ & $95.4 \% *$ & NR \\
\hline de.Souza et al 2010 & PBAC & NR & $94 \%$ & NR \\
\hline B.Chattopdhyay et al 2011 & PBAC & $82.5 \%$ & $91.7 \%$ & $\mathrm{P}<0.001$ \\
\hline
\end{tabular}

*median value, NR- not recorded

Serum ferritin is a marker of body iron stores. HMB is associated with decreased levels of serum ferritin. Reduction in menstrual blood loss after LNG-IUCD insertion is found to be effective in improving hemoglobin \& serum ferritin levels (Table 5). In our study we neither recommended nor discouraged the intake of oral iron supplements. We believe this can be a confounding factor in our study and might have interfered with improvement in $\mathrm{Hb}$ and serum ferritin levels.
Unscheduled vaginal spotting is the frequent cause of discontinuation. In our study we found spotting in $44.6 \%$ of patients at the end of six months. This finding corroborates with the findings of Rathnamala M Desai who found spotting in $32.5 \%$ of patients at the end of six months. Kriplani et al found it to be $20.68 \%$ of patient after six months. A prior counseling of the patients can decrease the discontinuation rate. ${ }^{11-12}$ 
Table5: Comparison of present study with other studies in improvement of haemoglobin.

\begin{tabular}{|c|c|c|c|c|}
\hline Studies & 0 Month & 3 Months & 6 Months & 12 Months \\
\hline Present study & $10.13 \pm 1.38 \mathrm{gm} / \mathrm{dl}$ & $\begin{array}{l}11.5 \pm 1.09 \mathrm{gm} / \mathrm{dl} \\
P<0.0001\end{array}$ & $\begin{array}{l}12.62 \pm 0.8 \mathrm{gm} / \mathrm{dl} \\
P<0.0001\end{array}$ & 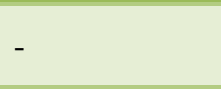 \\
\hline J. Kerstein et al 1990 & NR & N.S & $\mathrm{P}<0.001$ & - \\
\hline Tang \& Lo 1994 & 10.1 & N.S & $12.5 \mathrm{P}<0.05$ & - \\
\hline Barrington et al 1997 & NR & N.S P=0.1133 & - & - \\
\hline G.A Irvine et al 1998 & NR & N.S & - & - \\
\hline Hurskainen et al 2001 & $12.7 \pm 13$ & NR & NR & $13.5 \pm 9 \mathrm{P}<0.05$ \\
\hline Bilian Xiao et al 2003 & 12.15 & $13.03 \mathrm{P}<0.0001$ & $13.2 \mathrm{P}<0.001$ & - \\
\hline A.Kriplani et al 2007 & - & N.S & N.S & $\mathrm{P}=0.000$ \\
\hline Endrikat et al 2009 & 12.5 & - & - & $13.6 \mathrm{P}<0.001$ \\
\hline A.Kaunitz et al 2012 & 12.4 & NR & $13.4 \mathrm{P}<0.001$ & - \\
\hline $\begin{array}{l}\text { B.Chattopdhyay et al } \\
2011\end{array}$ & $9.8 \pm 1.26$ & $10.59 \pm 1.19 \mathrm{P}<0.001$ & $11.54 \pm 1.7 \mathrm{P}<0.001$ & - \\
\hline Shabaan et al 2011 & _- & - & - & $\mathrm{P}<0.05$ \\
\hline Mawet et al 2014 & $12.2 \pm 1.5$ & - & - & $13.2 \pm 1.4$ \\
\hline
\end{tabular}

LNG-IUCD markedly improves dysmenorrhoea. $94.73 \%$ patients were relieved of dysmenorrhoea at the end of three months. The similar finding was also seen in study by B. Chattopdhyay et al and A. Kriplani et al where relief in dysmenorrhea was seen in $85 \%$ and $77.5 \%$ respectively at the end of 3 months. ${ }^{12,13}$

The decrease in endometrial thickness is due to the antiproliferative effect of LNG-IUCD on endometrium, causing endometrial suppression, decidualization, and atrophy of glands as well as vascular changes. Two of our patients suffering from simple endometrial hyperplasia without atypia showed marked reduction in ET within 6 months of LNG-IUCD insertion. LNG-IUCD was effective in treatment of endometrial hyperplasia in these patients. We found that LNG-IUCD was effective in patients with small submucosal fibroids or uterine size upto 12 weeks with multiple fibroid but none of them distorting uterine cavity.

Out of total 3 expulsions in our study, 2 expulsions occurred in patients with submucosal fibroids and one expulsion occurred in patient with adenomyoma; both the conditions were distorting the uterine cavity. This finding corroborates with the finding of A.Kriplani et al where they found that the expulsion of device was more common among patients with a submucosal fibroid (15.4\%) than among those with other fibroid types (7.9\%) and among those with idiopathic menorrhagia (4.2\%). A.Kriplani et al concluded that non- receptiveness of certain uteri can be the cause of expulsion. ${ }^{12,14}$

In our study we did not find any significant reduction in fibroid size after 6 months. This is in corroboration with the study by A. Kriplani et al who did not find any significant change in leiomyoma volume even after 2 years of LNG-IUCD insertion. Murat Naki et al and Shawki et al also found no significant change in fibroid volume in 6 months. In contrast to this, Magal Haes et al found significant change in leiomyoma volume after 3 years. ${ }^{14-17}$

Patients with anovulatory cycles suffer from loss of progesterone effect on the endometrium leading to proliferation of endometrium due to unopposed action of estrogen. Also, the recent theory suggests that the absence of progesterone results in reduced endometrial stromal cell factor, reduced plasminogen activator inhibitor-1 production, increased matrix metalloproteinase activity and increased angiogenic factor expression. This all leads to vascular instability and impaired hemostasis finally leading to abnormal uterine bleeding. ${ }^{18}$ LNG- IUCD is effective in the management of HMB due to Ovulatory dysfunction. However, we did not find any significant differences between reduction in menstrual blood in patients with profilerative endometrium and secretory endometrium.

Hormonal side effects due to LNG-IUCD are usually minor and do not affect the quality of life of the patients.

The strength of this study and the high success rate (94\%) could be attributed to correct fundal placement of LNGIUCD and 24 hours accessibility provided to study population. A confounder in the study was that iron tablets were taken by some patients on their own, which could have resulted in higher $\mathrm{Hb}$ and ferritin levels. Another drawback of the study was the short follow up period of 6 months. It remains to be seen how many patients become amenorrhic or if the device expels after prolonged use.

\section{CONCLUSIONS}

We conclude that LNG-IUCD is an effective non-surgical alternative to a common problem of HMB and anaemia in patients desiring to conserve uterus. It showed significant reduction in menstrual blood loss and improvement in 
hemoglobin and serum ferritin even within a short period of three months. Also, LNG-IUCD was highly successful in treating dysmenorrhoea and endometrial hyperplasia. Correct fundal placement of the device and hysteroscopic evaluation of endometrial cavity were important aspects that should be kept in mind to avoid treatment failure. Spotting was the only bothersome side-effect but proper counseling of the patients allayed all the fears and increased acceptance. The patients are still in our follow up and continue to show acceptance and improvement in their symptoms.

\section{ACKNOWLEDGEMENTS}

Dr. Pushpa Singh, HOD, OBGYN, PGIMER, RML Hospital, New Delhi.

Funding: LNG-IUCD was in hospital supply

Conflict of interest: None declared

Ethical approval: The study was approved by the Institutional Ethics Committee

\section{REFERENCES}

1. Hallberg L, Hogdahl AM, Nilsson L, Rybo G. Menstrual blood loss- a population study. Variation at different ages and attempts to define normality. Acta Obstet Gynecol Scand. 1966;45:320-51.

2. Cole SK, Billewicz WZ, Thomson AM. Sources of variation in menstrual blood loss. J Obstet Gynaecol Br Commonw. 1971;78:933-9.

3. Hallberg L, Hogdahl AM, Nilsson L, Rybo G. Menstrual blood loss and iron deficiency anemia. Acta Med Scand. 1966;180(5):639-50.

4. National Collaborating Centre for Women's and Children's Health. Heavy menstrual bleeding. Available at www.nice.org.uk.http:// www.nice.org.uk/nicemidea/pdf/CG44FullGuideline s.pdf. Published January 2007. Accessed on 26 September 2015.

5. Coulter A, Peto V, Jenkinson C. Quality of life and patient satisfaction following treatment for menorrhagia. Fam Pract. 1994;11(4):394-401.

6. National Family Health Survey (NFHS-III), 20052006.

Available

at http://www.nfhsindia.org/pdf/India.pdf. Accessed on 26 September 2015.

7. Gupta B, Mittal S, Misra R, Deka D, Dadhwal V. Levonorgestrel-releasing intrauterine system vs. transcervical endometrial resection for dysfunctional uterine bleeding. Int $\mathrm{J}$ Gynaecol Obstet. 2006;95(3):261-6.

8. Magon N, Chauhan M, Goel P, Malik S, Kapur K, Kriplani A, et al. Levonorgestrel intrauterine system: current role in management of heavy menstrual bleeding. J Midlife health. 2013;4(1):8-15.

9. Higham JM, O'Brien PM, Shaw RW. Assessment of menstrual blood loss using a pictorial chart. British J Obstet Gynaecol. 1990;97:734-9.

10. Silverberg SG, Haukkamaa M, Arko H, Nilsson CG, Luukkainen T. Endometrial morphology during long-term use of levonorgestrel-releasing intrauterine devices. Intern J Gynecol Pathol: Official Journal of the International Society of Gynecological Pathologists. 1986;5:235-41.

11. Desai R. Efficacy of levonorgestrel releasing intrauterine system for the treatment of menorrhagia due to benign uterine lesions in perimenopausal women. J Midlife Health. 2012;3(1):20-3.

12. Kriplani A, Singh B.M, Lal S, Agarwal N. Efficacy, acceptability and side effects of the levonorgestrel intrauterine system for menorrhagia. Intern $\mathbf{J}$ Gynecol Obstet. 2007;97:190-4.

13. Chattopdhyay B, Nigam A, Goswami S, Chakravarty P.S. Clinical outcome of Levonorgestrel intra-uterine system in idiopathic menorrhagia. Eur rev med pharmacol sci. 2011;15:764-8.

14. Kriplani A, Awasthi D, Kulshrestha V, Agarwal N. Efficacy of the levonorgestrel-releasing intrauterine system in uterine leiomyoma. Int $\mathbf{J}$ of Gynecol Obstet. 2012;116:35-8.

15. Murat Naki M, Tekcan C, Ozcan N, Cebi M. Levonorgestrel releasing intrauterine device insertion ameliorates leiomyoma-dependent menorrhagia among women of reproductive age without a significant regression in the uterine and leiomyoma volumes. Fertil Steril. 2010;94(1):371-4.

16. Shawki O, El-Sherbiny W, Saber W et al. Treatment of heavy menstrual bleeding associated with uterine leiomyoma with the levonorgestrel-releasing intrauterine system. Gynecol Surg. 2009;6(4):331-7.

17. Magalhães J, Aldrighi JM, de Lima GR. Uterine volume and menstrual patterns in users of the levonorgestrel-releasing intrauterine system with idiopathic menorrhagia or menorrhagia due to leiomyomas. Contraception. 2007;75(3):193-8.

18. Lockwood C. Mechanism of Normal and Abnormal Endometrial bleeding. Menopause. 2011;18(4):40811.

Cite this article as: Malik R, Gupta J, Singh P, Yadav P. Levonorgestrel intrauterine contraceptive device in heavy menstrual bleeding: our experience in a tertiary level government hospital. Int J Reprod Contracept Obstet Gynecol 2016;5:327-33. 